\title{
Role of sildenafil citrate therapy in pregnant women with foetal growth restriction and oligohydrominos from Northern India
}

\author{
Priyanka Joshi $^{1}$, Madhubala Chouhan ${ }^{1}$, Nidhi Choudhary ${ }^{1}$, Abhishek Singh ${ }^{2 *}$
}

\begin{abstract}
${ }^{1}$ Department of Obstetrics and Gynecology, Rabindra Nath Tagore Medical College, Udaipur, Rajasthan, India
${ }^{2}$ Department of Community Medicine, SHKM Government Medical College, Mewat, Haryana, India
\end{abstract}

Received: 18 October 2018

Accepted: 12 November 2018

\author{
*Correspondence: \\ Dr. Abhishek Singh, \\ E-mail: abhishekparleg@gmail.com
}

Copyright: () the author(s), publisher and licensee Medip Academy. This is an open-access article distributed under the terms of the Creative Commons Attribution Non-Commercial License, which permits unrestricted non-commercial use, distribution, and reproduction in any medium, provided the original work is properly cited.

\begin{abstract}
Background: No specific treatment is available for severe early-onset IUGR. To best of my knowledge, very few studies have assessed the potential benefit of Sildenafil therapy targeted to improve perinatal outcomes in pregnancies complicated by severe early-onset IUGR in Indian pregnant women.

Methods: The present hospital based prospective study was carried out on one hundred ANC pregnant women with early and late fetal growth restriction and oligohydrominos at Pannadhai Mahila Chikatsalya, Rabindra Nath Tagore (RNT) Medical College, Udaipur, during Jan to Dec 2017. Sildenafil citrate $25 \mathrm{mg}$ three times in a day was administered until delivery. Study subjects were subjected to fetal Doppler and ultrasound twice a week after the Sildenafil administration.

Results: After sildenafil therapy, out of total 45 cases of IUGR alone, 39 cases $(86.66 \%)$ had improvement. Out of 35 cases of oligohydramnios alone, 28 cases $(80 \%)$ had improvement. Out of 20 cases having both IUGR and Oligohydramnios 16 had improvement $(80 \%)$ and only 4 cases did not show any improvement. Among gestation age 27-30 weeks group at the time of admission, there were total 10 cases out of which $5(50 \%)$ had early premature delivery (32-34 weeks), 3 (30\%) had late premature delivery (34-37 weeks) and 2 cases (2\%) had term delivery i.e. between 37-39 weeks after giving sildenafil treatment.

Conclusions: The findings of the present study indicate that sildenafil citrate may offer a potential therapeutic strategy to improve outcomes in pregnant women facing foetal growth restriction and oligohydrominos.
\end{abstract}

Keywords: Intrauterine growth restriction/oligohydramnios, Perinatal outcome, Sildenaphil citrate therapy

\section{INTRODUCTION}

In the current scenerio, no specific evidence-based therapy exists for intrauterine growth restriction (IUGR), placental insufficiency and oligohydramnios, the major causes of perinatal mortality and morbidity.

The burden of IUGR is very high in our country. ${ }^{1}$ More than $50 \%$ of stillbirths are associated with IUGR and $10 \%$ of perinatal mortality is a consequence of IUGR. ${ }^{2,3}$ Survival rates for severely growth-restricted fetuses very remote from term ( $<28$ weeks of gestation) are dismal. ${ }^{4,5}$ An important cause of IUGR is placental insufficiency, caused by a failure of placental trophoblast to adequately invade and transform maternal spiral arteries in early pregnancy. ${ }^{6,7}$ Sildenafil citrate (type 5 phosphodiesterase inhibitor) vasodilates the myometrial arteries isolated from women with IUGR-complicated pregnancies. ${ }^{8}$

Sildenafil citrate enhances amino acid availability in the conceptus and fetal growth in an ovine model of intrauterine growth restriction. 
In human, the use of sildenafil citrate in IUGR cases revealed encouraging results such as better foetal abdominal circumference (AC) growth, rise in liquor volume and positive Doppler changes with improved perinatal outcome and reduction in hospital admission rate. ${ }^{9-11}$

But there is no evidence of the benefit of using sildenafil citrate in the treatment of IUGR associated with impaired placental circulation. ${ }^{12}$

The present study was therefore planned to evaluate the effectiveness of sildenafil citrate type 5 phosphodiesterase inhibitor in pregnant women with early and late onset foetal growth restriction and oligohydrominos.

\section{METHODS}

The present hospital based prospective study was carried out on one hundred ANC pregnant women with early and late fetal growth restriction and oligohydrominos at Pannadhai Mahila Chikatsalya, Rabindra Nath Tagore (RNT) Medical College, Udaipur, during the year Jan 2017 to Dec 2017.

\section{Inclusion criteria}

- $\quad$ Cases aged 18-40 years; gestation age between 27-36 weeks;

- Early onset or late onset I.U.G.R.

- (AC and/ or EFW (10th centile with or without Doppler changes).

- A.F.I. <8; pregnancy induced hypertension present/ absent and Booked cases.

\section{Exclusion criteria}

- Known cases of aneuploidy, anomaly.

- Syndrome or congenital infection.

- If there was plan of induction; patients with reversal of end diastolic flow (REDF).

Unbooked cases and in mothers with cardiovascular morbidity were also excluded from the study. Cases were given Sildenafil if their pregnancy was complicated by severe early onset IUGR (ultrasound estimation of fetal AC of <5th percentile) with an estimated probability of intact survival of less than $50 \%$.

Sildenafil citrate $25 \mathrm{mg}$ three times in a day was administered until delivery. USG or colour Doppler was repeated after 15 days.

Study subjects were assessed regularly for blood pressure measurement, complete blood count, weight gain, blood serum creatinine, uric acid aspartate transaminase, bilirubin, and albumin. Fetal assessment included fortnightly fetal Doppler studies, AFI, fetal biophysical profile twice a week and bi weekly NST. Study subjects were also monitored for side-effects like headache, palpitation, flushing and visual disturbance.

Mode of termination of pregnancy was decided depending on the clinical condition of patients and the indications.

Injection betamethasone $12 \mathrm{mg}$ I.M. 2 doses at $24 \mathrm{hrs}$ apart will be administered to all pregnant women who have crossed 28 weeks of gestation to promote foetal lung maturity.

Study subjects were subjected to fetal Doppler and ultrasound twice a week after the Sildenafil administration. Uterine and umbilical artery, MCA and ductus venosus Doppler was performed. Changes were noted down before and after administration of drug.

Amniotic fluid volume, fetal AC was assessed once in 15 days for fetal growth velocity. At the time of delivery, details such as baby weight, APGAR score, Colour of the liquor (Meconium present or absent) and NICU admissions were noted. Informed consent was taken from patients.

The study protocol was approved by the institutional ethical committee. The collected data was entered into Microsoft-Excel 2007, coding of the variables was done. After cleaning, data was subsequently analyzed using SPSS version 20.0 software.

Interpretation of the collected data was done by using appropriate statistical methods. Statistical analysis included $\chi^{2}$-test (Chi square test) to compare proportions, and independent samples t-test and paired student's ' $t$ ' test to compare continuous variables.

A value of $\mathrm{p}<0.05$ was considered as significant in all statistical analysis.

\section{RESULTS}

One hundred ANC pregnant women were subjected to sildenafil citrate therapy with early and late fetal growth restriction and oligohydrominos to evaluate its effectiveness. Mean gestational age at the time of delivery was 36.4 weeks.

Among gestation age 27-30 weeks group at the time of admission, there were total 10 cases out of which 5 (50 $\%$ ) had early premature delivery (32-34 weeks), 3 (30\%) had late premature delivery (34-37 weeks) and 2 cases $(2$ $\%$ ) had term delivery i.e. between 37-39 weeks after giving sildenafil treatment (Table 1). 
Table 1. Continuation of pregnancy after intervention at different gestational age $(\mathrm{n}=\mathbf{1 0 0})$.

\begin{tabular}{|c|c|c|c|c|c|c|c|c|c|}
\hline \multirow{3}{*}{$\begin{array}{l}\text { Gestational age at time of } \\
\text { admission }\end{array}$} & \multicolumn{9}{|c|}{ Gestation age at time of delivery (in weeks) } \\
\hline & \multicolumn{3}{|c|}{$\begin{array}{l}\text { Early premature (32-34 } \\
\text { weeks) }\end{array}$} & \multicolumn{3}{|c|}{$\begin{array}{l}\text { Late premature (34-37 } \\
\text { weeks) }\end{array}$} & \multicolumn{3}{|c|}{ Term (37-39 weeks) } \\
\hline & $\mathrm{N}$ & $\%$ & p-value & $\mathrm{N}$ & $\%$ & p-value & $\mathrm{N}$ & $\%$ & p-value \\
\hline 27-30 weeks $(n=10)$ & 5 & 50 & 0.000 & 3 & 30 & 0.003 & 2 & 20 & 0.004 \\
\hline $30-32$ weeks $(n=60)$ & 3 & 5 & 0.018 & 29 & 48.33 & 0.000 & 28 & 46.67 & 0.000 \\
\hline $32-34$ weeks $(n=20)$ & 0 & 0 & -- & 4 & 20.00 & 0.003 & 16 & 80.00 & 0.000 \\
\hline $34-36$ weeks $(n=10)$ & 0 & 0 & _- & 0 & 0 & - & 10 & 100 & 0.000 \\
\hline
\end{tabular}

$* \mathrm{p}$ - value for paired t test at $5 \%$ level of significance. Mean gestational age at time of delivery $=36.363 \pm 1.48$ weeks. $\mathrm{p}$ value in all cases depicted was less than 0.005 which reflects that the drug Sildenafil have statistically significant.

The above table depicts the effect of sildenafil citrate on IUGR and Oligohydramnios. We found that after sildenafil therapy, out of total 45 cases of IUGR alone, 39 cases had improvement $(86.66 \%)$ and only 6 cases did not show any improvement. Out of 35 cases of oligohydramnios alone, 28 cases had improvement (80 $\%$ ) and only 7 cases did not show any improvement. Out of 20 cases having both IUGR and Oligohydramnios 16 had improvement $(80 \%)$ and only 4 cases did not show any improvement. (Table 2)

Table 2. Distribution of pregnant patients on effect of sildenafil citrate on IUGR/ oligohydramnios $(n=100)$.

\begin{tabular}{|c|c|c|c|}
\hline $\begin{array}{l}\text { Types of } \\
\text { abnormality }\end{array}$ & $\begin{array}{l}\text { Before } \\
\text { sildenafil }\end{array}$ & $\begin{array}{l}\text { After } \\
\text { sildenafil }\end{array}$ & Improve \% \\
\hline IUGR alone & 45 & 6 & 86.66 \\
\hline $\begin{array}{l}\text { Oligohydramnios } \\
\text { alone }\end{array}$ & 35 & 7 & 80 \\
\hline $\begin{array}{l}\text { IUGR + } \\
\text { Oligohydramnios }\end{array}$ & 20 & 4 & 80 \\
\hline
\end{tabular}

\section{DISCUSSION}

Subjects faced with the diagnosis of severe early-onset IUGR have two standard-of-care options as of today: expectant management with maternal lifestyle modification and maternofetal surveillance or pregnancy termination. Neither is attractive. No specific treatment is available for severe early-onset IUGR. To best of my knowledge, very few studies have assessed the potential benefit of Sildenafil therapy targeted to improve perinatal outcomes in pregnancies complicated by severe earlyonset IUGR in indian pregnant women. We made a modest attempt to evaluate the effectivness sildenafil citrate therapy on one hundred ANC pregnant women with early and late fetal growth restriction and oligohydrominos.

In this study we observed that among gestation age 27-30 weeks group at the time of admission, there were total 10 cases out of which $5(50 \%)$ had early premature delivery (32-34 weeks), 3 (30\%) had late premature delivery (3437 weeks) and 2 cases (2\%) had term delivery i.e. between 37-39 weeks after giving sildenafil treatment.
Premalatha HL et al studied 100 cases from 22 weeks to 36 weeks in Karnataka. ${ }^{13} 10$ cases were studied from 22 weeks, of which 8 cases continued their pregnancy for 8 weeks, and 2 stillbirths occurred. 10 cases were studied at 34 weeks, of which in 9 cases pregnancy continued for 2 weeks and in 1 case for 4 weeks with no fetal and maternal morbidity and mortality. Thus, authors concluded that Sildenafil therapy had improved the perinatal outcome and reduced NICU admissions. These effects could be explained with improvement of foetal perfusion and the resultant nutrient availability. Von Daldeszen et al from Canada observed that the mean GA at eligibility was 21 weeks +1 day in sildenafil naïve group and 22 weeks +4 days in sildenafil treated group. The mean GA at time of delivery was 25 weeks +6 days in sildenafil naïve group and 27 weeks+1day in sildenafil treated group. ${ }^{8}$ Sildenafil treatment was associated with increased fetal AC growth [odds ratio, 12.9; 95\% confidence interval (CI), 1.3, 126; compared with institutional Sildenafil-naive early-onset IUGR controls].

Another study from Chhattisgarh considered IUGR in respect of $\mathrm{AC}$, as it is one of the most sensitive indicators of IUGR. ${ }^{14}$ They got improved AC of $70 \%$ in treated group compared to $34 \%$ in non-treated group. The difference between the two was significant. Cases reported by Panda $\mathrm{S}$ et al on Indian patients reported improvement of doppler blood flow indices and improvement of pregnancy outcomes following Sildenafil administration post diagnosis. ${ }^{15}$ Ferreira et al from Canada conducted a descriptive case series of all hospitalized pregnant women who received sildenafil for severe IUGR. Study included 19 hospitalized pregnant women who received sildenafil for severe IUGR. ${ }^{16}$ Sildenafil was started at an average of 25 weeks +3 days in average dosage of $20 \mathrm{mg}$ orally 3 times/day until delivery. Before sildenafil, estimated average fetal weight was 558g [237, 1208] and increased to an average of $807 \mathrm{~g}$ at delivery and with an average weight gain of $249 \mathrm{~g}$. However, there was no control arm in his study.

\section{CONCLUSION}

To conclude, the empirical evidences of the current study indicate that Sildenafil citrate may offer a potential 
therapeutic strategy to improve outcomes in pregnant women facing foetal growth restriction and oligohydrominos. Sildenafil may represent a novel intervention for such pregnancies. Data presented here are insufficient to guide decision making about the use of Sildenafil citrate in pregnancies complicated by severe early-onset IUGR. Thus, randomised controlled trial studies are warranted to support or refute our findings.

Funding: No funding sources Conflict of interest: None declared

Ethical approval: The study was approved by the Institutional Ethics Committee

\section{REFERENCES}

1. Murki S, Sharma D. Intrauterine growth retardation: A review article. J Neonatal Biol. 2014;3(135):2167897.

2. Froen JF, Gardosi JO et al. Restricted fetal growth in sudden intrauterine unexplained death. Acta Obstet Gynecol Scand. 2004;83(9):801-7.

3. Richardus JH, Graafmans WC, et al. Differences in perinatal mortality and suboptimal care between 10 European regions: results of an international audit BJOG 2003;110(2):97-105.

4. Petersen SG, Wong SF, Urs P, Gray PH, Gardener GJ. Early onset, severe fetal growth restriction with absent or reversed end- diastolic flow velocity waveform in the umbilical artery: perinatal and longterm outcomes. Aust NZ J Obstet Gynaecol 2009;49(1):45-51.

5. Bilardo CM, Wolf H, Stigter RH, Ville Y, Baez E, Visser GH, et al. Rela- tionship between monitoring parameters and perinatal outcome in severe, early intrauterine growth restriction. Ultrasound Obstet Gyne- col 2004;23(2):119-25.

6. Olofsson P, Laurini RN, Marsál K. A high uterine artery pulsatility index reflects a defective development of placental bed spiral arteries in pregnancies complicated by hypertension and fetal growth retardation. Eur J Obstet Gynecol Reprod Biol. 1993;49(3):161-8.

7. Sağol S, Sağol O, Ozdemir N. Stereological quantification of placental villus vascularization and its relation to umbilical artery Doppler flow in intrauterine growth restriction. Prenat Diagn. 2002; 22(5):398-403.

8. Von Dadelszen P, Dwinnell S, Magee LA, Carleton BC, Gruslin A, Lee B, Lim KI, Liston RM, Miller SP, Rurak D, Sherlock RL. Sildenafil citrate therapy for severe early-onset intrauterine growth restriction. BJOG: Int J Obstet Gynaecol. 2011;118(5):624-8.

9. Dastjerdi MV, Hosseini S, Bayani L. Sildenafil citrate and uteroplacental perfusion in fetal growth restriction. J Res Med Sci. 2012;17(7):632-6.

10. Dunn L, Greer R, Flenady V, Kumar S. Sildenafil in pregnancy: a systematic review of maternal tolerance and obstetric and perinatal outcomes. Fet Diagnos Ther. 2017;41(2):81-8.

11. Miller SL, Loose JM, Jenkin G, Wallace EM. The effects of sildenafil citrate (Viagra) on uterine blood flow and wellbeing in the intrauterine growthrestricted fetus. Am J Obstet Gynecol. 2009;200(1):102-e1.

12. Maged M, Wageh A, Shams M, Elmetwally A. Use of sildenafil citrate in cases of intrauterine growth restriction (IUGR); a prospective trial. Taiwanese $\mathbf{J}$ Obstet Gynecol. 2018;57(4):483-6.

13. Premalatha HL, Raghupathi KMS, Srinivas DNB, Venkatesh, Laxmi Kanth. Study of effect of sildenafil citrate in pregnant women with intrauterine growth restriction/ oligohydramnios. Int $\mathrm{J}$ Reprod Contracept Obstet Gynecol. 2016;5(9):3094-7.

14. Singh A, Daharwal A, Kujur A, Awasthi P. Effect of sildenafil on IUGR. Int J Reprod Contracept Obstet Gynecol 2017;6(5):1806-9.

15. Panda S, Das A. Sildenafil Citrate in Fetal Growth Restriction. J Reprod Infertil. 2014;15(3):168-9.

16. Ferreira E, Léveillée D, Iglesias MH, Brochet MS. O-OBS-MFM-PhD-065 Sildenafil Use During Pregnancy for Intrauterine Growth Restriction: A Case Series. J Obstet Gynaecol Canada. 2016;38(5): 486.

Cite this article as: Joshi $\mathrm{P}$, Chouhan M, Choudhary N, Singh A. Role of sildenafil citrate therapy in pregnant women with foetal growth restriction and oligohydrominos from Northern India. Int J Reprod Contracept Obstet Gynecol 2019;8:165-8. 